\title{
Dawson-Type Vanadium-Substituted Tungstophosphate- Modified ITO Electrode: Preparation, Characterization and Electrochemical Determination of Dopamine
}

\author{
Xinming Wang ${ }^{1}$, Yuanqing Zhao ${ }^{1}$, Di Zhang ${ }^{1,2}$, Shuang Rong ${ }^{3}$, Huiyuan Ma ${ }^{1, *}$ \\ ${ }^{1}$ Key Laboratory of Green Chemical Engineering and Technology of College of Heilongjiang \\ Province, College of Chemical and Environmental Engineering, Harbin University of Science and \\ Technology, Harbin 150040, China \\ ${ }^{2}$ School of Materials Science and Engineering, Harbin Institute of Technology, Harbin 150001, China \\ ${ }^{3}$ Heilongjiang electric power research institute, Harbin 150032, China \\ *E-mail: mahy017@163.com
}

doi: $10.20964 / 2019.04 .08$

Received: 19 November 2018 / Accepted: 17 January 2019 / Published: 10 March 2019

In this work, we describe a robust composite film-modified indium tin oxide (ITO) electrode with improved detection capabilities for an example neurotransmitter, dopamine (DA). The composite film was developed by the combination of a Dawson-type vanadium tungstophosphate, $\alpha_{2}-$ $\mathrm{K}_{7} \mathrm{P}_{2} \mathrm{~W}_{17} \mathrm{VO}_{62} \cdot 18 \mathrm{H}_{2} \mathrm{O}\left(\mathrm{P}_{2} \mathrm{~W}_{17} \mathrm{~V}\right)$, and cationic chitosan $(\mathrm{CS})$ via a layer-by-layer (LbL) self-assembly technique. The composite film-modified electrode presents excellent electrochemical catalytic activity towards dopamine (DA) with a linear response over the range of $1.25 \times 10^{-8} \mathrm{M}$ to $3.04 \times 10^{-4} \mathrm{M}$. The proposed system responds selectively to dopamine with a low detection limit of $0.18 \mu \mathrm{M}(\mathrm{S} / \mathrm{N}=3)$, a high sensitivity of $0.23 \mu \mathrm{A} \mu \mathrm{M}^{-1}$ and a quick response time. As a result, the prepared composite film materials with these superior properties show promising applicability in electrochemical sensors.

Keywords: composite film; polyoxometalate; electrochemistry; dopamine

\section{FULL TEXT}

(C) 2019 The Authors. Published by ESG (www.electrochemsci.org). This article is an open access article distributed under the terms and conditions of the Creative Commons Attribution license (http://creativecommons.org/licenses/by/4.0/). 